\title{
Neurology
}

Issue: Volume 52(4), 10 March 1999, pp 719-724

Copyright: (C) 1999 American Academy of Neurology

Publication Type: [Articles]

DOI: 10.1212/WNL.52.4.719

ISSN: 0028-3878

Accession: 00006114-199903100-00012

[Articles]

\section{Risk of Alzheimer's disease in relatives of Parkinson's disease patients with and without dementia}

Marder, K. MD, MPH; Tang, M.-X. PhD; Alfaro, B. MS; Mejia, H. MS; Cote, L. MD; Louis, E. MD, MSc; Stern, Y. PhD; Mayeux, R. MD, MSc

\section{Author Information}

From the Gertrude H. Sergievsky Center (Drs. Marder, Tang, Alfaro, Mejia, Cote, Louis, Stern, and Mayeux) and the Departments of Neurology (Drs. Marder, Alfaro, Mejia, Cote, Louis, Stern, and Mayeux), and Psychiatry (Drs. Stern and Mayeux), College of Physicians and Surgeons; and the Divisions of Epidemiology and Biostatistics (Dr. Tang), School of Public Health at Columbia University (Dr. Mayeux), New York, NY. Supported by federal grants AG07232, AG10963, and RR00645, and the Parkinson's Disease Foundation. Received July 29, 1998. Accepted in final form November 7, 1998.

Address correspondence and reprint requests to Dr. Karen Marder, G.H. Sergievsky Center, 630 West 168th Street, New York, NY 10032.

\section{Article abstract}

Objective: To determine whether first-degree relatives of PD patients with dementia were at increased risk for the development of $A D$ compared with first-degree relatives of nondemented PD patients and nondemented normal subjects from the community.

Methods: A structured family history interview was administered to 146 nondemented PD patients, 120 patients with PD and dementia, and 903 normal subjects from the community to ascertain the presence of $A D$ among parents and siblings of these subjects. Cox proportional hazards models with double censoring techniques for missing information were used to model the risk of $A D$ among relatives.

Results: No increase in risk of AD was found among parents of patients with PD and dementia or parents of nondemented PD patients compared with parents of normal subjects. However, siblings of demented PD patients were three times as likely (relative risk $[\mathrm{RR}]=3.2,95 \%$ confidence interval $[\mathrm{Cl}]=1.1$ to $9.4, p<$ 0.04 ) as siblings of normal subjects to develop $A D$. When only siblings $>65$ years of age were considered, there was a fivefold increase in risk of $A D$ among siblings of demented PD patients compared with siblings of normal subjects $(\mathrm{RR}=4.9,95 \% \mathrm{Cl}=1.1$ to $21.4, p<0.03)$. The risk of $A D$ was also increased for female relatives, regardless of whether the woman was a relative of a demented PD patient, a nondemented PD 
patient, or a normal subject. Ethnicity and $A P O E$ genotype did not affect dementia status among relatives.

Conclusions: The increased risk of AD in siblings of demented PD patients compared with siblings of normal subjects supports the possibility of familial aggregation of AD and PD with dementia.

Dementia is a common, functionally disabling complication of idiopathic PD.1 Patients with PD are almost twice as likely as normal subjects to become demented over a 2-year period.2 No single cause of dementia in patients with PD has been established. The neuropathologic findings in patients with PD and dementia (PDD) include concomitant $A D$, cortical Lewy bodies,3 degeneration of the medial substantia nigra, 4 neurites in the CA2 region of the entorhinal cortex,5,6 and neuropil threads in the pre-layer of entorhinal cortex.7 Currently, there is no reliable way to distinguish among these causes, either clinically or by risk factor profile.

We hypothesized that when dementia in the setting of PD is caused by $A D$, then the risk factors for AD should be present in patients with PDD. We previously found no association between the presence of an APOE[varepsilon]4 allele in patients with PDD in comparison with nondemented patients with PD (PDND) and normal subjects of similar age and ethnicity in the community of Washington Heights-Inwood in northern Manhattan, New York City.8 However, we have also reported that a family history of dementia was six times as high among patients with PDD as among PDND patients.9 The PDD patients were older than PDND patients, and it is likely that the relatives of demented patients were older.

To further evaluate the possibility of familial aggregation of AD and PDD, we administered structured family history interviews to 146 PDND patients, 120 PDD patients, and 903 nondemented normal subjects from Washington Heights-Inwood. Our primary aim was to determine whether first-degree relatives of PDD patients were at increased risk for the development of AD compared with first-degree relatives of PDND patients and normal subjects from the community.

Methods. Criteria for patients with idiopathic $P D$. All patients were participants in a community-based study of PD in Washington Heights in northern Manhattan, New York City. A PD registry was created in 1988 from several sources, including regional hospitals, private practitioners in the community, senior centers, health maintenance organizations, federal and state agencies, and newspaper and radio advertisements. Patients followed at two other local hospitals and by the Health Insurance Providers of New York were also asked to participate. Analysis of the sample indicated nearly complete participation.10

Idiopathic PD was defined according to clinical and research criteria.11-13 Patients with secondary PD were excluded, as were those with progressive supranuclear palsy, Shy-Drager syndrome, striatonigral degeneration, or olivopontocerebellar atrophy. Patients who reported cognitive impairment before the onset of the motor signs of PD were excluded. Patients with both PD and essential tremor were not excluded.

All patients underwent an annual standard neuropsychologic assessment for the diagnosis of dementia based on Diagnostic and Statistical Manual of Mental Disorders, 3rd ed., revised (DSM-III-R) criteria.14 Based on this assessment, patients were rated as demented or nondemented. 
Criteria for normal subjects All normal subjects were volunteers over age 60 years. Normal subjects were identified from a random sample of Medicare recipients from the same geographic region as the patients. None of the normal subjects was a first-degree relative or spouse of a patient. All normal subjects underwent neurologic examinations, and none had evidence of PD or stroke. The same neuropsychologic battery used to assess patients was administered to all normal subjects, and none met the DSM-III-R criteria for dementia.

Family history questionnaire. A structured family history interview for the ascertainment of AD, PD, and other neurologic disorders was read to each patient and normal subject.15 If the patient was demented at the time, the family history was obtained from the most knowledgable informant or an informant in conjunction with the patient. A separate questionnaire was completed by the proband or informant for each first-degree relative.

For the determination of $A D$, if either of two screening questions was answered affirmatively, a set of follow-up questions was asked to ascertain the presence of $A D$ and determine a level of certainty of the diagnosis. If the screening questions were not endorsed, no further questions were asked, and the relative was assumed not to have $A D$. The screening questions were "Did the family member have memory loss, senility, dementia, AD, hardening of the arteries, or other mental changes?" and "Was the person unable to care for himself/herself?"

The sensitivity and specificity of the first screening question for clinically diagnosed AD was previously determined in a sample of 180 siblings of 127 probands with AD.16 Only the validity of the first screening question was assessed, because there were no cases in which the second screening question was endorsed without the first question also being endorsed. All siblings underwent neurologic and neuropsychologic examinations, on the basis of which the prevalence of AD among siblings was $31 \%(56 / 180)$. Pathologic confirmation of the clinical diagnoses was not available for any of the siblings. The sensitivity of the screening question for $\mathrm{AD}$ was $64 \%$ and the specificity was $83 \% .16$ The education of the informant, the relationship of the informant to the proband (spouse and siblings were better informants than were children of probands), and personal rather than telephone interviews were associated with improved sensitivity.16

Based on the screening questions and the ensuing 10 follow-up questions, an algorithm was created to assign a level of certainty to the diagnosis of $A D$ (Table 1). A definite diagnosis was reserved for autopsy-proven AD. Diagnoses were stratified further into probable, possible, uncertain, and unlikely AD. For the analyses reported here, family members with definite, probable, possible, and uncertain AD were considered to have AD (liberal criteria). All analyses were repeated using a more restricted definition (definite, probable, and possible), all of which required a physician to make a diagnosis of AD. The results were similar to those obtained by the liberal criteria. 


\section{Definite $A D$}

\section{Autopsy-proven AD}

Probable $A D$ (must have 1 and 2)

1. At least two of the following reported:

Gradual and progressive loss of memory

Confused and disoriented most of the time

Difficulty recognizing family members

2. Diagnosis of $\mathrm{AD}$ made by a neurologist or a psychiatrist

Possible $A D$ (must have 1 and 2)

1. Must meet item 1 for probable AD

2. Diagnosis of $\mathrm{AD}$ made by a physician (not a neurologist or a psychiatrist)

\section{Uncertain $A D$}

Satisfies item 1 for probable AD

No diagnosis of $\mathrm{AD}$ made by any physician

\section{Unlikely $A D$}

Does not satisfy item 1 for probable $\mathrm{AD}$

No diagnosis of $\mathrm{AD}$ made by any physician

Table 1 Diagnostic algorithm for AD

Statistical analysis. The baseline characteristics of PDND patients, PDD patients, and normal subjects were compared by use of Student's $t$-tests and analysis of variance (ANOVA) for continuous variables and chisquare tests for categorical variables.

To determine whether there was an association between proband group (PDND, PDD, normal subject) and AD in first-degree relatives, analyses were confined to the first-degree relatives who were $>30$ years of age. Only parents and siblings were included in the analyses. 
We used Cox proportional hazards models with double censoring techniques for missing information on age at onset of $A D$ to model the relative risk for AD among first-degree relatives of PDND and first-degree relatives of PDD compared with first-degree relatives of normal subjects.15,17 Left-censoring was applied if the relative was known to have AD but the onset date was unknown. Right-censoring was applied if the relative had never been diagnosed with $A D$ or if the relative had died without a diagnosis of AD.17 The onset date, defined as the date of the first symptom of $A D$ as reported by the proband or informant, was used to determine the age at onset of AD. In the Cox model, age was treated as a continuous variable. The distribution of age at onset of AD was compared among the three groups of relatives (PDND patients, PDD patients, normal subjects). Covariates included in the model included gender of the relative, ethnicity (Caucasian, African American, Hispanic) and $A P O E$ status stratified as the presence or absence of at least one APOE-[varepsilon]4 allele. Because information on education of the relatives was extremely limited, we included education of the proband in the model. To adjust more carefully for age of the relatives, these analyses were repeated to include only relatives $>65$ years of age, rather than all relatives $>30$ years of age.

Because of the possibility that the accuracy of reporting of AD in parents and siblings of probands would differ, the analyses were performed separately for parents of patients compared with parents of normal subjects, and siblings of patients compared with siblings of normal subjects, adjusting for relevant covariates. In addition, because awareness of AD has increased in the past quarter century, siblings of patients and normal subjects would be more likely to have received a diagnosis of AD than parents.

Last, to validate the family history interview, the family history information was compared with the diagnosis based on neurologic and neuropsychologic examination in 47 siblings of PD patients.

Results. The PDND patients were significantly younger and better educated than PDD patients and normal subjects (table 2). The percent of relatives in each group diagnosed with AD based on the alogrithm did not differ across groups. Based on the algorithm, there were 61 relatives of PD patients and 164 relatives of normal subjects who had AD. When the 26 relatives of PDND patients were considered, four (15.4\%) had definite AD, four (15.4\%) had probable AD, 10 (38.5\%) had possible AD, and eight (30.8\%) had uncertain AD. One (2.9\%) relative of the 35 PDD patients had definite AD, three (8.6\%) had probable AD, 21 (60\%) had possible AD, and 10 (28.6\%) had uncertain PD. Among relatives of normal subjects, 13 (7.9\%) had definite AD, 32 (19.5\%) had probable AD, 76 (46.3\%) had possible AD, and $43(26.2 \%)$ had uncertain AD. None of the algorithm-based diagnoses in the relatives were pathologically confirmed. Two parents, each from a different PDND family, met the criteria for both AD and PD. Two siblings, each from a different PDD family, met the criteria for both AD and PD. One sibling from a normal subject family met the algorithm criteria for both AD and PD. 


\begin{tabular}{|c|c|c|c|}
\hline Characteristic & $\begin{array}{c}\text { PDND } \\
\text { patients, } \\
\mathrm{n}=146\end{array}$ & $\begin{array}{c}\text { PDD } \\
\text { patients, } \\
\mathrm{n}=120\end{array}$ & $\begin{array}{c}\text { Normal } \\
\text { subjects, } \\
\mathrm{n}=903\end{array}$ \\
\hline Age, y, mean (SD) & $69.6(10.5)$ & $76.9(8.2)$ & $74.2(5.6)^{*}$ \\
\hline Sex, \% M/\% F & $47 / 53$ & $58 / 42$ & $32 / 68^{*}$ \\
\hline \multicolumn{4}{|l|}{ Ethnicity, n } \\
\hline White & 79 & 58 & 233 \\
\hline African American & 15 & 12 & 148 \\
\hline Hispanic & 50 & 48 & 517 \\
\hline Other & 2 & 2 & $5^{*}$ \\
\hline $\begin{array}{l}\text { Education, } y, \text { mean } \\
\text { (SD) }\end{array}$ & $11.6(5)$ & $9.5(4.8)$ & $9.4(4.5)^{*}$ \\
\hline $\begin{array}{l}\text { No. relatives } \\
\quad \text { (parents \& sibs } \\
\quad>30 \mathrm{y})\end{array}$ & 583 & 547 & 2865 \\
\hline $\begin{array}{c}\text { Prevalence of } \mathrm{AD} \text { in } \\
\text { relatives }(\%)\end{array}$ & $26(4.5)$ & $35(6.4)$ & $164(5.7)$ \\
\hline \multicolumn{4}{|l|}{$\begin{array}{l}\text { APOE genotype in } \\
\text { proband, } \%\end{array}$} \\
\hline $4 / 4$ & $0 \quad(\mathrm{n}=0)$ & $1.6(\mathrm{n}=1)$ & $1.9(\mathrm{n}=15)$ \\
\hline $4 /-$ & $26.0(\mathrm{n}=27)$ & $19.7(\mathrm{n}=12)$ & $26.6(\mathrm{n}=208)$ \\
\hline$-1-$ & $74.0(\mathrm{n}=77)$ & $78.7(\mathrm{n}=48)$ & $71.5(\mathrm{n}=560)$ \\
\hline
\end{tabular}

* Significant difference between the three groups. $p<0.001$. PDND $=$ PD without dementia; PDD $=$ PD with dementia.

Table 2 Demographic characteristics of probands 
Relationship of proband status to $A D$ in relatives. The age at onset of $A D$ among relatives of PDND patients and relatives of PDD patients was compared with that of normal subjects (reference), adjusting for relative gender, relative ethnicity, proband education, and proband $A P O E$-[varepsilon]4 status. When all relatives (parents and siblings) were included in the model, there was no difference in risk of AD among relatives of PDND patients compared with normal subjects (relative risk $[\mathrm{RR}]=0.9,95 \%$ confidence interval $[\mathrm{Cl}]=0.6$ to $1.3, p<0.55$ ) or relatives of PDD patients ( $\mathrm{RR}=1.2,95 \% \mathrm{Cl}=0.7$ to $2.0, p<0.4)$ compared with normal subjects. Female relatives were at increased risk $(R R=1.7,95 \% \mathrm{Cl}=1.3$ to $2.4, p<0.0008)$ compared with male relatives, after adjustment for proband group (PDND patients, PDD patients, normal subjects) and education of the proband. Ethnicity and $A P O E$-[varepsilon]4 status were not associated with $A D$ in the relatives.

The analysis was repeated to examine the parents and siblings separately (table 3). The distribution of age at onset of AD did not differ among parents of PDND patients, PDD patients, and normal subjects. Therefore, parents of demented and nondemented PD patients were not at increased risk for the development of AD compared with parents of normal subjects. However, siblings of PDD had over three times the risk of developing AD compared with normal subjects $(R R=3.2,95 \% \mathrm{Cl}=1.1$ to $9.4, p<0.04)$, after adjustment for proband education and relative gender. Because only four siblings of PDND patients were affected, interpretation in this group is problematic. Although it appears that being a relative of a PDND patient is protective for the development of dementia $(\mathrm{RR}=0.3,95 \% \mathrm{Cl}=0.1$ to $0.8, p<0.03$ ), the small number of affected relatives in this group makes this interpretation doubtful.

\begin{tabular}{lccc}
$\begin{array}{l}\text { Relationship to } \\
\text { proband }\end{array}$ & $\begin{array}{c}\text { Total number of } \\
\text { relatives }\end{array}$ & $\begin{array}{c}\text { Affected } \\
\text { relatives (AD) }\end{array}$ & $\begin{array}{c}\text { RR } \\
(95 \% \mathrm{CI})\end{array}$ \\
\hline Parent of control & 1516 & 102 & 1 (reference) \\
Parent of PDND & 258 & 22 & $1.3(0.8-2.1)$ \\
Parent of PDD & 203 & 17 & $0.9(0.5-1.7)$ \\
Siblings of control & 1349 & 62 & 1 (reference) \\
Siblings of PDND & 325 & 4 & $0.3(0.1-0.8)$ \\
& & & $p<0.04$ \\
Siblings of PDD & 344 & 18 & $3.2(1.1-9.4)$ \\
& & & $p<0.04$ \\
\hline
\end{tabular}

$\mathrm{PDND}=\mathrm{PD}$ without dementia; $\mathrm{PDD}=\mathrm{PD}$ with dementia; $\mathrm{RR}=$ relative risk; $\mathrm{CI}=$ confidence interval.

Table 3 Relative risk of AD in two separate analyses: parents of PDND patients and parents of PDD patients compared with parents of normal subjects, and siblings of PDND patients and siblings of PDD patients compared with siblings of normal subjects adjusted for gender, ethnicity, and APOE and education of the proband 
To further adjust for age of the relatives, the analyses were confined to relatives $>65$ years of age. The mean age of parents of normal subjects $>65$ was 79.2 years (SD 8.8), that of parents of PDND patients $>65$ was 81.3 years (SD 9.4), and that of parents of PDD patients $>65$ was 82.1 years (SD 9.4). There was no difference in risk of $A D$ among the parents of PDND patients, PDD patients, and normal subjects.

The mean age of the 706 siblings of normal subjects $>65$ years of age was 75.8 years (SD 7.3), that of the 139 siblings of PDND patients $>65$ was 75.1 years (SD 6.9), and that of 230 siblings of PDD patients $>65$ was 76.2 years (SD 6.4). Siblings of PDD patients were at increased risk for the development of $A D(R R=4.9,95 \% \mathrm{Cl}=$ 1.1 to $21.4, p<0.03)$ compared with siblings of normal subjects. There was a trend for a protective effect in siblings of PDND patients ( $R R=0.25,95 \% \mathrm{Cl}=0.06$ to $1.0, p<0.52)$ compared with siblings of normal subjects.

Risk among women compared with men. Women (mothers and sisters) were at increased risk for the development of AD compared with men, after adjustment for proband group and education of the proband. The RR for mothers was $2.1(95 \% \mathrm{Cl}=1.5$ to $3.1, p<0.001)$ compared with fathers. The RR for sisters compared with brothers was $1.6(95 \% \mathrm{Cl}=1.0$ to $2.4, p<0.04)$.

Validity of family history data. We examined the validity of the diagnosis of $A D$ in siblings ascertained by the family history questionnaire in 47 siblings of PD probands who underwent neurologic and neuropsychologic examination. Based on the neuropsychologic examination, two siblings were demented and 45 were nondemented. Only one of the two siblings considered demented according to the examination was identified by the family history questionnaire. The sensitivity of the algorithm was therefore $50 \%$. Of 45 siblings, 44 were correctly identified by the family history interview as not having AD based on neuropsychologic testing and clinical examination. The specificity of the algorithm was $98 \%$ (44/45).

Discussion. Using a structured family history interview, we found no increase in risk of AD among first-degree relatives of 146 nondemented PDND patients or first-degree relatives of 120 PDD patients in comparison with the risk of $A D$ in first-degree relatives of 903 community normal subjects. However, when parents and siblings were examined separately, siblings of PDD patients had a threefold increase in risk of AD compared with siblings of normal subjects. When only relatives $>65$ were considered, the risk of AD increased to 4.9 for the siblings of PDD patients compared with siblings of normal subjects. The risk for female relatives compared with male relatives was increased almost two-fold and was seen for both mothers and sisters of probands. Ethnicity and the presence of $A P O E$-[varepsilon]4 in the proband did not influence the risk of AD for the relatives of PDND or PDD patients compared with normal subjects. As previously demonstrated in relatives of AD patients and normal subjects, the family history interview for AD was highly specific but not very sensitive to AD in firstdegree relatives. 16

Risk factors for $A D$ in patients with $P D D$. One approach to identifying the subset of PDD patients who have AD is to examine whether the risk factors for AD are present more often among PDD patients than in PDND patients or normal subjects. We and others 8 have found no association between APOE-[varepsilon] 4 and dementia in PD. Conversely, as in AD, we found that a history of estrogen use was protective against the development of dementia in the setting of PD.18 Age, severity of extrapyramidal signs, and depressive symptoms have also been shown to be predictive of incident dementia among both AD 19 and PD patients. 2 
A family history of $A D$ has been shown to be a risk factor for $A D$ in numerous studies, with $R R$ ranging from 2.52 to 3.81.20-23 In the current study, when only siblings were considered, the risk of AD in the PDD patients compared with normal subjects was 3.2, well within the range of estimates for first-degree relatives of $A D$ patients.

Risk of $A D$ in siblings compared with parents. There is no consensus on whether siblings or parents of probands with $A D$ are at increased risk for the development of $A D$, with some studies demonstrating no difference,21,24 others demonstrating increased risk among siblings,22,25 and others demonstrating increased risk among parents.23 One possible explanation for the differences in risk estimates may be the accuracy of reporting among the informants. In most family studies, specificity is consistently high and does not change based on the relationship of informant and relative. By contrast, sensitivity may vary depending on the relationship of the informant to the relative. We previously reported that a family history of AD provided by siblings of probands with $A D$ on other siblings in the family was more sensitive (100\%) than family history provided by children of the proband with AD on their aunts/uncles $(61 \%)$, whereas specificity was $81 \%$ when provided by siblings and $80 \%$ when provided by children of the proband.16

When asked to be the informants on probands with specific medical conditions, generally spouses and offspring are the best informants on events experienced by the proband during adult life, and accuracy depends on the frequency of contact. Siblings appear to be best able to describe events occurring in early life and characteristics of the proband's family.26

In this study, the proband or an informant reported on AD among family members. Sensitivity estimates are twice as high when the proband is the target of the interview, rather than the relative. Perhaps this is because disease in the proband is often more severe than disease in the relative.27 There may also be a cohort effect, in that parents would be less likely to be reported as having $A D$ than siblings because of lack of awareness of $A D$ when the parents were alive.

Gender differences. In the Multi-Institutional Research in Alzheimer Genetic Epidemiology (MIRAGE) study,23 female relatives had a $13 \%$ higher risk of developing AD by age 93 than male relatives. In another study, female relatives of $A D$ patients were at increased risk of $A D$ compared with male relatives (odds ratio [OR] 2.27, 95\% $\mathrm{Cl}=1.22$ to 4.2) (Consortium to Establish a Registry for Alzheimer's Disease).21 Others have not found sexspecific differences.22,24 In the current study, both mothers and sisters of PD patients had twice the risk of AD compared with fathers and brothers.

Risk of $P D$ in relatives of $A D$ patients. Whether relatives of $A D$ patients have a higher risk of PD compared with normal subjects is controversial; such a risk is increased in some studies 25,28 but not others.21,29,30 Hofman et al.28 found an increased risk of PD among first-degree relatives of AD patients compared with relatives of normal subjects ( $\mathrm{RR} 2.9,95 \% \mathrm{Cl}=1.1$ to 8.3). When stratified by gender, the risk of PD was increased for men with $A D(R R=7.6, \mathrm{Cl}=0.9$ to 63.6) compared with male normal subjects. The risk of PD among women with $A D$ compared with female normal subjects was lower ( $R R=1.8, C l=0.5$ to 6.3). 
In a recent clinic-based analysis of the risk of $A D$ and $P D$ in first-degree relatives of $A D$ and PD patients and their spousal normal subjects, the risk of $A D$ but not PD was increased among relatives of $A D$ patients, and the authors concluded that there was no familial association between AD and PD. The risk of PD was increased in relatives of PD patients compared with spousal normal subjects, using a Cox proportional hazard model.

Risk of $A D$ in relatives of $P D$ patients. In the same study,31 those authors found no increase in risk of $A D$ among relatives of PDD patients compared with PDND patients, but there were only 15 PDD patients.31

Farrer et al.24 compared the risk of $A D$ among first-degree relatives of $A D$ patients with the risk of $A D$ among first-degree relatives of PD patients. In that study, PD patients were considered normal subjects because at that time PD was not considered to be a "genetic" disease. No difference was found in risk of AD between the two groups. The cumulative incidence of AD among relatives of AD patients was $24 \%$ by age 93 and $16 \%$ by age 90. Those authors found that the risk of $A D$ among relatives of PD patients was significantly later in life (>age 80) than among relatives of AD patients. In the only other examination of risk of AD among relatives of PDD and PDND patients, we previously reported that a family history of AD was six times as common in PDD patients as in PDND patients followed up at a medical center.9

The strengths of this study include the large samples size and the fact that all probands underwent neurologic and neuropsychologic examinations to determine dementia status. Normal subjects were neurologically and neuropsychologically normal and were randomly selected from the same community as the patients. Information on each relative was obtained separately by a structured interview, and a high specificity of the interview for the presence of AD has been demonstrated.

Limitations include the lack of pathologic confirmation of the cause of dementia in these patients. As in any disease of late onset, many of the relative on whom information was obtained were dead.

We have found the family history interview to be highly specific but only modestly sensitive. Comparable sensitivities and specificities have been found for family histories of other disorders when compared with direct interviews with relatives. The sensitivity of family histories for psychiatric disorders ranges from $30 \%$ to $60 \% 27,32$ compared with direct interviews, whereas the sensitivity of reporting of severe headache and migraine among probands with epilepsy was $48 \%$ and $44 \%$, respectively, compared with self-report.33 We examined whether there is differential underreporting of $A D$ among the three groups of probands. Using the same family history interview, we previously demonstrated an increased risk of PD among first-degree relatives of PD patients (RR 2.3, 95\% Cl=1.3 to 4.0). When the analysis was confined to PDND patients and normal subjects, the risk remained elevated $(\mathrm{RR} 2.8,95 \% \mathrm{Cl}=1.4$ to 5.5$) .15$ Therefore, it does not appear that there was differential reporting of PD in relatives of PDND patients compared with PDD patients. To further examine the issue of underreporting (low sensitivity), we determined the proportion of men and women relatives reported to have AD within each group (PDND patients, PDD patients, and normal subjects) and found no significant differences. We could not demonstrate underreporting of AD by gender within any of the groups (PDND, PDD, normal subjects). In future studies, sensitivity could be improved by obtaining information from multiple informants and by conducting in-person examinations of relatives whenever possible. 
Dementia may be an important marker of susceptibility to both PD and AD. Dementia has been reported in both the Contursi kindred 34,35 and the Spellman-Meunter kindred 36 and may be part of the phenotype in those families. Further work on refining the risk factors for dementia in PD may lead to a broader understanding of the pathogenesis of both PD and AD.

\section{Acknowledgment}

The authors thank Nicole Schupf, PhD, for her thoughtful suggestions.

\section{References}

1. Mayeux R, Denaro J, Hemenegildo N, et al. A population-based investigation of Parkinson's disease with and without dementia: relationship to age and gender. Arch Neurol 1992;49:492-497. [Context Link]

2. Marder K, Tang M-X, Cote L, Stern Y, Mayeux R. The frequency and associated risk factors for dementia in patients with Parkinson's disease. Arch Neurol 1995;52:695-701. Bibliographic Links |[Context Link]

3. McKeith IG, Galasko D, Kosaka K, et al. Consensus guidelines for the clinical and pathological diagnosis of dementia with Lewy bodies (DLB): report of the consortium on DLB international workshop. Neurology 1996;47:1113-1124. Ovid Full Text | Bibliographic Links |[Context Link]

4. Rinne JO, Rummukainen J, Paljarvi L, Rinne UK. Dementia in Parkinson's disease is related to neuronal loss in the medial substantia nigra. Ann Neurol 1989;26:47-50. [Context Link]

5. Churchyard A, Lees. The relationship between dementia and direct involvement of the hippocampus and amygdala in Parkinson's disease. Neurology 1997;49:1570-1576. Ovid Full Text | Bibliographic Links [Context Link]

6. Kim H, Gearing M, Mirra SS. Ubiquitin-positive CA2/3 neurites in hippocampus coexist with cortical Lewy bodies. Neurology 1995;45:1768-1770. [Context Link]

7. Braak H, Braak E, Yilmazer D, et al. Cognitive impairment in Parkinson's disease: amyloid plaques, neurofibrillary tangles, and neuropil threads in the cerebral cortex. J Neural Trans Basic Neurosci Neurol Sect Psychiatry Sect 1990;2:45-57. [Context Link]

8. Marder K, Maestre G, Cote L, et al. The apolipoprotein epsilon 4 allele in Parkinson's disease with and without dementia. Neurology 1994;44:1330-1331. Bibliographic Links | [Context Link]

9. Marder K, Flood P, Cote L, Mayeux R. A pilot study of risk factors for dementia in Parkinson's disease. Mov Disord 1990;5:156-161. [Context Link]

10. Mayeux R, Marder K, Cote L, et al. The frequency of idiopathic Parkinson's disease by age, ethnic group, and sex in northern Manhattan, 1988-1993. Am J Epidermiol 1995;142:820-827. [Context Link]

11. Ward CD, Gibb WR. Research diagnostic criteria for Parkinson's disease. In: Streiffler MB, Korczyn AD, 
Melamed E, Youdin MB, eds. Parkinson's disease: anatomy, pathology and therapy. New York: Raven Press, 1990:245-249. [Context Link]

12. Hughes AJ, Daniel SE, Kilford L, Lees AJ. Accuracy of clinical diagnosis of idiopathic Parkinson's disease: a clinico-pathological study of 100 cases. J Neurol Neurosurg Psychiatry 1992;55:181-184. Bibliographic Links |[Context Link]

13. Hughes AJ, Ben-Schlomo Y, Daniel SE, Lees AJ. What features improve the accuracy of clinical diagnosis in Parkinson's disease: a clinicopathologic study. Neurology 1992;42:1142-1146. Bibliographic Links [Context Link]

14. American Psychiatric Association. Diagnostic and statistical manual of mental disorders, rev. 3rd ed. Washington, DC: American Psychiatric Press, Inc., 1987. [Context Link]

15. Marder K, Tang M-X, Mejia H, et al. Risk of Parkinson's disease among first-degree relatives: a communitybased study. Neurology 1996;47:155-160. [Context Link]

16. Devi G, Marder K, Schofield P, Tang M-X, Stern Y, and Mayeux R. Validity of family history for the diagnosis of dementia among siblings of patients with late-onset Alzheimer's disease. Genet Epidemiol 1998;15:215-223.

Bibliographic Links | [Context Link]

17. Tang M-X, Maestre G, Tsai W-Y, et al. Relative risk of Alzheimer's disease and age-at-onset distributions, based on APOE genotypes among elderly African-Americans, Caucasians, and Hispanics in New York City. Am J Hum Genet 1996;58:574-584. Bibliographic Links | [Context Link]

18. Marder K, Tang M-X, Alfaro B, et al. Postmenopausal estrogen use and Parkinson's disease with and without dementia. Neurology 1998;50:1141-1143. Ovid Full Text | Bibliographic Links | [Context Link]

19. Richards M, Stern Y, Mayeux R. Subtle extrapyramidal signs can predict the development of dementia in elderly individuals. Neurology 1993;43:2184-2188. Bibliographic Links | [Context Link]

20. The Canadian Study of Health and Aging. The Canadian study of health and aging: risk factors for Alzheimer's disease in Canada. Neurology 1994;44:2073-2080. Bibliographic Links |[Context Link]

21. Silverman JM, Raiford K, Edland S, et al. The Consortium to Establish a Registry for Alzheimer's Disease (CERAD). Part VI. Family history assessment: a multicenter study of first-degree relatives of Alzheimer's disease probands and nondemented spouse controls. Neurology 1994;44:1253-1259. [Context Link]

22. van Duijn CM, Clayton D, Chandra V, et al. Familial aggregation of Alzheimer's disease and related disorders: a collaborative re-analysis of case-control studies. Int J Epidemiol 1991;20(suppl 2):S13-S19. Bibliographic Links | [Context Link]

23. Lautenschlager N, Cupples L, Rao S, et al. Risk of dementia among relatives of Alzheimer's disease 
patients in the MIRAGE study: What is in store for the oldest old? Neurology 1996;46:641-650. [Context Link]

24. Farrer L, O'Sullivan D, Cupples L, Growdon J, Myers R. Assessment of genetic risk for Alzheimer's disease among first-degree relatives. Ann Neurol 1989;25:485-493. Bibliographic Links | [Context Link]

25. Amaducci LA, Fratiglioni L, Rocca WA, et al. Risk factors for clinically diagnosed Alzheimer's disease: a case-control study of an Italian population. Neurology 1986;36:922-931. Bibliographic Links | [Context Link]

26. Pickle LW, Brown LM, Blot WJ. Information available from surrogate respondents in case-control interview studies. Am J Epidemiol 1983;118:99-106. Bibliographic Links | [Context Link]

27. Ovaschel $\mathrm{H}$, Thompson WD, Belanger A, et al. Comparison of the family history method to direct interview. J Affect Dis 1982;4:49-59. [Context Link]

28. Hofman A, Shulte W, Tanja R, et al. History of dementia and Parkinson's disease in 1st degree relatives of patients with Alzheimer's disease. Neurology 1989;39:1589-1592. [Context Link]

29. Fratiglioni L, Ahlbom A, Viitanen M, Winblad B. Risk factors for late-onset Alzheimer's disease: a population-based, case control study. Ann Neurol 1993;33:258-266. [Context Link]

30. Huff FJ, Auerbach J, Chakravarti A, Boller F. Risk of dementia in relatives of patients with Alzheimer's disease. Neurology 1988;38:786-790. [Context Link]

31. Mickel SF, Broste SK, Hiner BC. Lack of overlap in genetic risks for Alzheimer's disease and Parkinson's disease. Neurology 1997;48:942-949. [Context Link]

32. Andreasen NC, Endicott J, Spitzer RL, Winokur G. The family history method using diagnostic criteria. Arch Gen Psychiatry 1977;34:1229-1235. [Context Link]

33. Ottman R, Hong S, Lipton R. Validity of family history data on severe headache and migraine. Neurology 1993;43:1954-1960. Bibliographic Links | [Context Link]

34. Polymeropoulos MH. Genetic complexity and Parkinson's disease. Science 1997;277:389. [Context Link]

35. Polymeropoulos MH, Lavedan C, Leroy E, et al. Mutation in the a-synuclein gene identified in families with Parkinson's disease. Science 1997;276:2045-2047. [Context Link]

36. Meunter MD, Forno LS, Kish SJ, et al. Hereditary form of Parkinsonism-dementia. Ann Neurology 1998;43:768-781. [Context Link]

\section{IMAGE GALLERY}




\section{Select All}

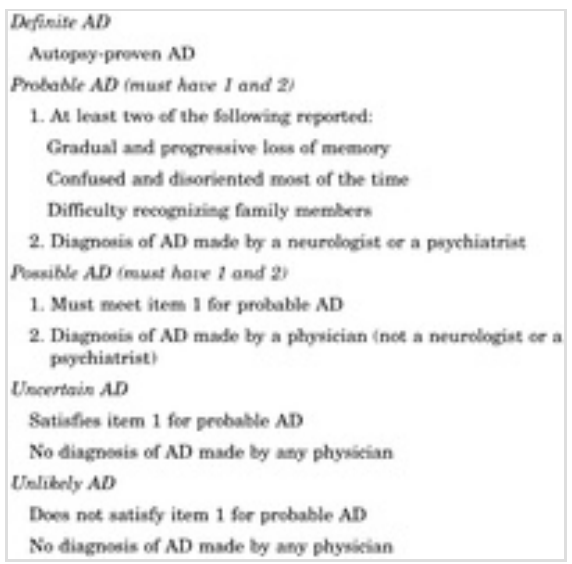

Table 1

\begin{tabular}{|c|c|c|c|}
\hline Chararteriatic & $\begin{array}{l}\text { PDND } \\
\text { patients. } \\
\mathrm{n}=146\end{array}$ & $\begin{array}{l}\text { PDD } \\
\text { patients, } \\
\mathrm{m}=120\end{array}$ & $\begin{array}{l}\text { Normal } \\
\text { nabjerta. } \\
n=903\end{array}$ \\
\hline Age, $y$, mean (SD) & $69.6(10.5)$ & 76.9 (8.2) & $74.2(5.6)^{\circ}$ \\
\hline $\operatorname{Sex}, \% \mathrm{~N} / \mathrm{F}$ & 4783 & 58442 & $3268 *$ \\
\hline \multicolumn{4}{|l|}{ Euhnixity, n } \\
\hline White & 29 & 58 & 233 \\
\hline African American & 15 & 12 & 148 \\
\hline Hispanie & so & 48 & 517 \\
\hline Other & 2 & 2 & $5^{*}$ \\
\hline $\begin{array}{l}\text { Edocation, } y \text {, mean } \\
\text { (SD) }\end{array}$ & $11.6(5)$ & $9.5(4.8)$ & $9.4(4.5 \%$ \\
\hline $\begin{array}{l}\text { No. relatives } \\
\quad \begin{array}{l}\text { (parents \& whe } \\
>30 y)\end{array}\end{array}$ & 503 & 567 & 2865 \\
\hline $\begin{array}{c}\text { Prevalence of } A D \text { in } \\
\text { relatives }(\Phi)\end{array}$ & $26(4.5)$ & $35(6.4)$ & $164(5.7)$ \\
\hline \multicolumn{4}{|l|}{$\begin{array}{l}\text { APOE gesotype in } \\
\text { proband, \% }\end{array}$} \\
\hline $4 / 4$ & 0 in $=0$ ) & 1.5 in $=1)$ & $1.9(\mathrm{n}=15)$ \\
\hline $4-$ & $26.0(\mathrm{i}-27)$ & $19.7(\mathrm{n}=12)$ & $26.6(n=208)$ \\
\hline$-\beta$ & $74.0(\mathrm{~s}-77)$ & $78.7(\mathrm{n}=48)$ & $71.5(\mathrm{n}=560)$ \\
\hline
\end{tabular}

Table 2

\begin{tabular}{|c|c|c|c|}
\hline $\begin{array}{l}\text { Relationahip to } \\
\text { proband }\end{array}$ & $\begin{array}{l}\text { Total number of } \\
\text { relatives }\end{array}$ & $\begin{array}{l}\text { Affected } \\
\text { relatives (AD) }\end{array}$ & $\begin{array}{c}\mathrm{RH} \\
\cos \% \mathrm{ct})\end{array}$ \\
\hline Parent of control & 1516 & 102 & 1 (refefence) \\
\hline Parent of PDND & 258 & 22 & $1.3(0.8-2.1)$ \\
\hline Parent of PDD & 203 & 17 & $0.9(0.5-1.7)$ \\
\hline Stblings of eentrol & 1349 & 62 & 1 (referenes) \\
\hline Siblines of PIDSD & 325 & 4 & $\begin{array}{c}0.3<0.1-0.8) \\
p<0.04\end{array}$ \\
\hline Siblines of PDD & 344 & 18 & $\begin{array}{c}3.2(1.1-9.4) \\
p<0.04\end{array}$ \\
\hline \multicolumn{4}{|c|}{$\begin{array}{l}\text { PDND - PD withost dementia: PDD - FD with dementia: RR = } \\
\text { relative riak: } \mathrm{CI} \text { = confidence interval. }\end{array}$} \\
\hline
\end{tabular}

Back to Top

About Us Contact Us Privacy Policy Terms of Use

(C) 2019 Ovid Technologies, Inc. All rights reserved. OvidUI_04.02.01.008, SourcelD HEAD 